\title{
Induction of Tetraploidy to Feverfew (Tanacetum parthenium Schulz-Bip.): Morphological, Physiological, Cytological, and Phytochemical Changes
}

\author{
Mohammad Majdi and Ghasem Karimzadeh ${ }^{\mathbf{1}}$ \\ Plant Breeding and Biotechnology Department, Faculty of Agriculture, Tarbiat \\ Modares University, P.O. Box 14115-336, Tehran, Iran
}

\author{
Mohammad A. Malboobi \\ National Institute of Genetic Engineering and Biotechnology (NIGEB) P.O. \\ Box 14155-6343, Tehran, Iran
}

\section{Reza Omidbaigi}

Horticulture Department, Faculty of Agriculture, Tarbiat Modares University, P.O. Box 14115-336, Tehran, Iran

\section{Ghader Mirzaghaderi}

Agronomy and Plant Breeding Department, Faculty of Agriculture, University of Kurdistan, Sanandaj, Iran

Additional index words. chlorophyll fluorescence, chromosome doubling, colchicine, DAPI, feverfew, flow cytometry, stomatal density, trichome density

\begin{abstract}
An efficient colchicine-mediated chromosome doubling of diploid feverfew followed by the morphophenological, physiological, phytochemical, and cytological changes of the obtained tetraploid plants was conducted. One-week-old seedlings of feverfew were treated with $0.05 \%$ (w/v) colchicine for $2,4,6,8$, and $24 \mathrm{~h}$. Tetraploid plants were regenerated after 4 months, showing significant changes in stomatal size and density; sizes of seed; flower, pollen, leaf, trichome, cell, nucleus, and parthenolide content; chromosome number; ploidy level; chlorophyll content index; and quantum efficiency of photosystem II. Such characteristics of induced tetraploid feverfews can be useful in medicinal and ornamental applications, e.g., the study of flower morphogenesis, trichome differentiation, and parthenolide biosynthesis. The increase in parthenolide in tetraploids of the next generation (selfed $T_{0}$ plants) showed that ploidy induction is a good breeding method for feverfew.
\end{abstract}

Feverfew (Tanacetum parthenium Schulz-Bip.) as a diploid species $(2 n=2 x=$ $18)$ in the family Asteraceae has been con-

Received for publication 12 June 2009. Accepted for publication 17 Nov. 2009

This study was financially supported by a grant from Tarbiat Modares University, Tehran, Iran. Mr. Majdi thanks Prof. Alison Ferrie (Senior Research Officer of NRC Plant Biotechnology Institute, Saskatoon, Saskatchewan, Canada) for reviewing the manuscript; Samad Nejad-Ebrahimi (Shahid Beheshti University, Tehran, Iran) for TLC analysis; and Seyed Hossein Mousavi, Iman Tabatabaei, and Abolfazl Jowkar (Agricultural Biotechnology Research Institute of Iran, Karaj) for their assistance in FCM analysis. We acknowledge Prof. David Smyth (School of Biological Sciences, Monash University, Melbourne, Australia) and Patrick Reeves (USDA-ARS, National Center for Genetic Resources Preservation, Fort Collins, CO) for their useful comments.

${ }^{1}$ To whom reprint requests should be addressed; e-mail karim_gh@modares.ac.ir. opment of tetraploid feverfew may play an important role in the generation of triploid lines. The latter may have higher productivity than either of the parental diploid or tetraploid feverfew plants (Yang et al., 2006). Tetraploid plants are usually larger than diploids and have enlarged leaves and flowers; hence, polyploid induction can be an effective method to increase biomass and to improve medicinal and ornamental characteristics. In the present study, the induction of polyploid on feverfew was examined and morphological, physiological, cytological, and phytochemical characteristics of diploid and induced-tetraploid plants were analyzed.

\section{Materials and Methods}

Polyploid induction. Seeds of diploid feverfew were germinated in petri dishes on filter paper at $25^{\circ} \mathrm{C}$. A drop of $0.05 \%(\mathrm{w} / \mathrm{v})$ colchicine solution was applied manually using a micropipette to newly emerged shoot tip meristems of 1-week-old seedlings. The roots were immersed in the colchicine solution for 0 (control), 2, 4, 6, 8, or $24 \mathrm{~h}$. For better absorption of colchicine, treated seedlings were left in enclosed petri dishes and gently shaken on a shaker at $25^{\circ} \mathrm{C}$ followed by $3 \times 3$-min washing in running distilled water. Seedlings were then transferred to new petri dishes on moist filter paper for 1 week. Each treatment consisted of three replicated petri dishes, each containing 30 seedlings. Seedlings were transferred to pots in an environmentally controlled growth room and covered with plastic under a $16-\mathrm{h} \cdot \mathrm{d}^{-1}$ photoperiod at a light intensity of $300 \mu \mathrm{mol} \cdot \mathrm{m}^{-2} \cdot \mathrm{s}^{-1}$ for 4 to 5 months until flowering and seed maturation.

Cytological measurements. To arrest cells in metaphase, germinated 0.5 -cm-length seedlings were chemically pretreated with $0.002 \mathrm{M}$ 8-hydroxyquinoline for $8 \mathrm{~h}$ at $4{ }^{\circ} \mathrm{C}$ and fixed in ethanol:glacial acetic acid $(\mathrm{v} / \mathrm{v}$ $3: 1)$ for $24 \mathrm{~h}$. Seedlings were hydrolyzed in 1 $\mathrm{M} \mathrm{HCl}$ for $10 \mathrm{~min}$ at $62{ }^{\circ} \mathrm{C}$ and stained with $1 \%(\mathrm{w} / \mathrm{v})$ aceto-orcein solution for $30 \mathrm{~min}$ at $25^{\circ} \mathrm{C}$. Root tips of the stained seedlings were excised and briefly flamed in a drop of $1 \%(\mathrm{w} /$ $\mathrm{v}$ ) aceto-orcein and then squashed in a drop of $45 \%(\mathrm{v} / \mathrm{v})$ acetic acid. Photographs were taken using a DP12 digital camera (Olympus Optical Co., Tokyo, Japan) interfaced to a BX50 Olympus microscope (Olympus Optical Co., Ltd., Tokyo, Japan). A composite sample of young leaves $(0.25 \mathrm{~g})$ from each plant and standard $(0.25 \mathrm{~g})$ was used for the identification of ploidy level by flow cytometry (FCM) (PAI; Partec, Münster, Germany); Rosa victoriana $(2 n=2 x=14)$ was used as a standard plant. Nuclei were extracted from leaves according to Yokoya et al. (2000). Leaf material from the internal standard and unknown feverfew samples was chopped in a petri dish resting on ice using a razor blade. Nuclei were released from the cells with the addition of $0.5 \mathrm{~mL}$ CyStain DNA one-step (Partec kit, CyStain DNA onestep Code No. 05-5004); then $1.5 \mathrm{~mL}$ was 
added and incubated for $5 \mathrm{~min}$ at root temperature (RT). The suspension of released nuclei was filtered through a $50-\mu \mathrm{m}$ CellTris disposable filter to remove cell debris. Stained nuclei were analyzed by the Partec PAI Flow Cytometer using ultraviolet excitation. The ratio of the fluorescence intensities of the G1 stage of the cell cycle of the Rosa victoriana and Tanacetum parthenium nuclei was used to determine the ploidy level. Four replications were used for FCM analysis.

Morphological and physiological measurements. Chlorophyll fluorescence induction kinetic parameters $\left(\mathrm{F}_{\mathrm{v}} / \mathrm{F}_{\mathrm{m}}\right.$, ratio of variable to maximum fluorescence) from the axial side of the leaf were measured using a PSM time-resolved fluorescence instrument (Plant Stress Meter; Biomonitor AB, Umea, Sweden) (Oquist and Wass, 1988). Leaves were dark-adapted for $30 \mathrm{~min}$ before measurement of fluorescence induction. The actinic irradiance used with the PSM was 250 $\mu \mathrm{mol} \cdot \mathrm{m}^{-2} \cdot \mathrm{s}^{-1}$. A CCM-200 instrument (OptiSciences, Tyngsboro, MA) was used to calculate the chlorophyll content index (CCI) based on absorbance measurements at 660 and $940 \mathrm{~nm}$ (Opti-Sciences Inc., 2002).

Length, width, and density of both stomata and trichomes were measured on the axial leaf surfaces by the impression method (Khazaei et al., 2009). The density of the stomata was counted at $20 \times$ magnification and the length and the width of stomata and trichomes were measured at $100 \times$ using a DP12 digital camera interfaced to a BX50 Olympus microscope (Olympus Optical Co., Ltd.) for 30 leaves from the three confirmed diploid and tetraploid plants by FCM. Pollen grains were collected from flowers at anthesis and their lengths were measured at $100 \times$ under the light microscope for 30 samples from the three confirmed diploid and tetraploid plants.

Phytochemical measurement. Flowers and leaves were dried for $5 \mathrm{~d}$ at RT and ground to a fine powder using a coffee grinder. For each replication, $300 \mathrm{mg}$ of powdered leaves or flowers was ultrasonicated (J.P. Selecta Group, Barcelona, Spain) in $3 \mathrm{~mL} \mathrm{MeOH}$ for $15 \mathrm{~min}$ at RT, centrifuged at $670 \mathrm{~g}$ for $5 \mathrm{~min}$, filtered and transferred to new vials, used for thin layer chromatography (TLC) and high-performance liquid chromatography (HPLC) analysis. Equal amounts $(10 \mu \mathrm{L})$ of each replications were applied to a TLC plate (silica gel 60 F254, $10 \times 10 \mathrm{~cm}$; Merck, Darmstadt, Germany) and developed. The mobile phase was n-hexaneEtOAc, $2+3(\mathrm{v} / \mathrm{v})$ (Abourashed, 2004). The CAMAG TLC system consisted of a linomat 5 autosampler, TLC scanner 3, and winCATS 1.2.2 Software (CAMAG, Muttens, Switzerland). Samples were applied in $4 \mathrm{~mm}$ length at $10-\mathrm{mm}$ intervals under a $\mathrm{N}_{2}$ stream. The position of the first track was $15 \mathrm{~mm}$. Development to a distance of $85 \mathrm{~mm}$ was performed on $10 \times 10$-cm Twin-thought camber (CAMAG). Chromatograms were evaluated for peak area after scanning with absorbance mode at $209 \mathrm{~nm}$ (Abourashed, 2004). Parthenolide amount of the selfed $\mathrm{T}_{0}$ tetraploids $\left(\mathrm{T}_{1}\right)$ and diploid (control) was analyzed by HPLC.
Equal amounts $(20 \mu \mathrm{L})$ of each replications were injected into the HPLC system (Waters ${ }^{\mathrm{TM}}$ 600 pump, Milford, MA) equipped with a 250 $\times 4.6 \mathrm{~mm} \mathrm{C}-18$ column ( $4 \mu \mathrm{m}$, Waters). The mobile phase was an isocratic $55 \%$ acetonitrile: $45 \%$ water at $1.5 \mathrm{~mL} \cdot \mathrm{min}^{-1}$ flow rate for 5 $\mathrm{min}$. The ultraviolet detector was set at $210 \mathrm{~nm}$ (Fonseca et al., 2005).

Statistical analysis. The effect of colchicine treatment time on survival rate and tetraploidy induction was analyzed by analysis of variance using a completely randomized design with three replications. Tetraploidy induction efficiency was calculated using the Bouvier et al. (1994) method as follows: induction efficiency $=\%$ seedling survival $\times$ $\%$ tetraploidy induction.

Induction efficiency for tetraploidy gives a range between 0 and 100, in which 100 indicates that all treated seedlings were tetraploids and 0 shows no tetraploidy induction occurred. Mean $(n=30)$ comparisons between diploid and tetraploid plants for stomatal and trichome densities, length, width, flower diameter and weight, pollen and seed size, CCI, quantum efficiency of photosystem II $\left(\mathrm{F}_{\mathrm{v}} / \mathrm{F}_{\mathrm{m}}\right)$, cell length, and nuclear diameter were assessed by Student's $t$ test.

\section{Results}

Ploidy induction. The effects of colchicine on tetraploid survival and induction were examined after anthesis (Table 1). In this analysis, nonflowering and chimera plants were not considered. The duration of colchicine treatment significantly affected survival and tetraploid induction $(P<$ 0.001 ; Table 1). Tetraploid induction increased when the duration of the colchicine treatment was increased; however, seedling survival decreased proportionally (Fig. 1). Mean comparison using Tukey's test showed no significant difference in the frequency of tetraploids between colchicine-free treatment (control, $0 \mathrm{~h}$ ), $2 \mathrm{~h}$ - and $24 \mathrm{~h}$-colchicinetreated, and among 4-, 6-, and 8-h colchicine-treated (Fig. $1 \mathrm{~A}$ ); at 4-h colchicinetreated, the survival was $50 \%$ (Fig. 1B). The colchicine induction efficiency was higher at 4-h to 8-h colchicine-treated (the maximum was $4.1 \%$ in 6 -h colchicine-treated; Fig. 1C) compared with that at $0-\mathrm{h}, 2-\mathrm{h}$, and $24-\mathrm{h}$ colchicine-treated. Tetraploid induction efficiency is a suitable parameter for the determination of best treatment for tetraploid determination because it considers both seedling survival and tetraploid rate production (Lehrer et al., 2008). No clear difference was observed in flowering time between control diploids and the tetraploids.

Morphophenological differences. The morphological characteristics of diploid and tetraploid plants were assessed to determine which characteristics might be useful for identifying tetraploid plants like the size of stomata, trichome, leave, and flower. Colchicine treatment delayed shoot growth in the first month after treatment, but afterward, both treated and nontreated seedlings grew

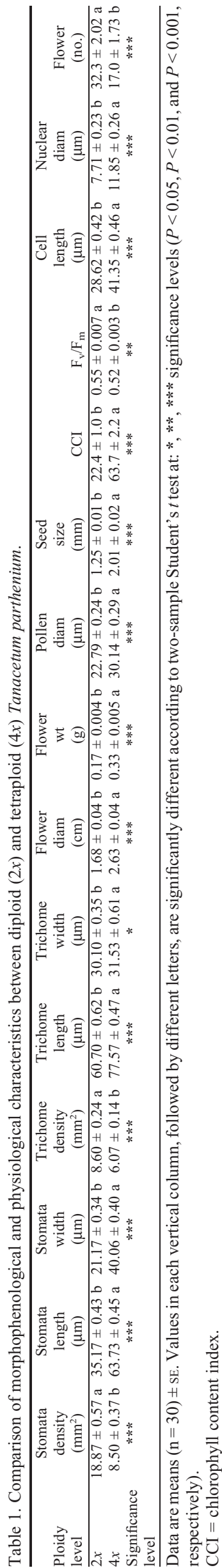


A

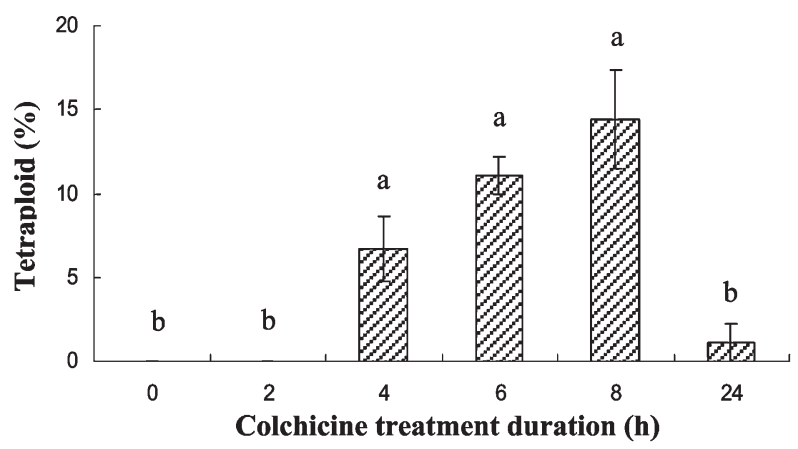

C

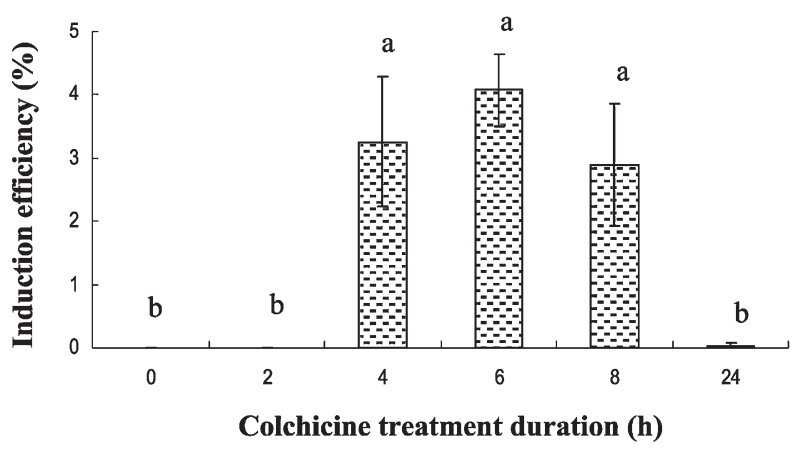

B

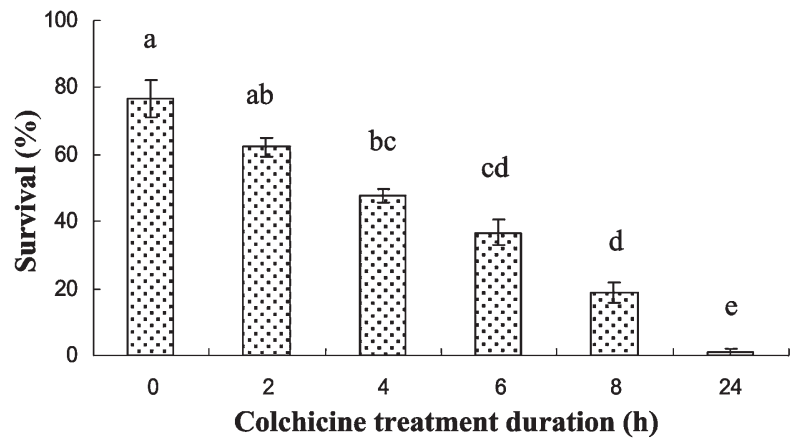

Fig. 1. Effects of colchicine treatment duration (h) on (A) tetraploid induction (\%) (B) survival (\%), and (C) induction efficiency in Tanacetum parthenium. Means followed by the same letters are not significantly different according to Tukey's test $(P>0.001)$. Bars represent means of three replicates $\pm \mathrm{SE}$.

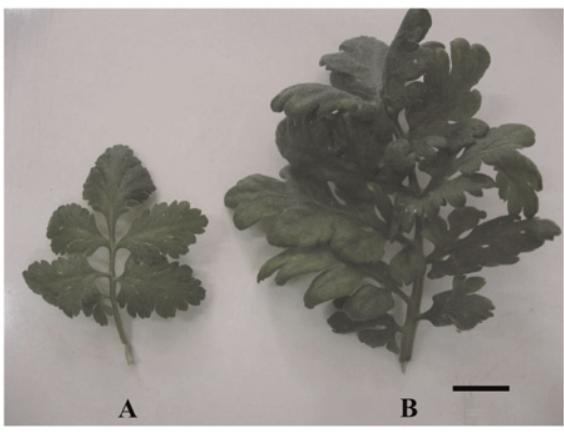

Fig. 2. Leaves of diploid (A) and tetraploid (B) Tanacetum parthenium. $\mathrm{Bar}=1 \mathrm{~cm}$.

similarly. In most cases, the first leaves of tetraploids had a distorted appearance, but the subsequent leaves appeared normal. The tetraploid plants had larger, thicker, deeper green leaves and were often curly (Fig. 2). Flower diameter and fresh weight of diploid and tetraploid plants was significantly $(P<$ 0.001 ) different (Fig. 3; Table 1). Flowers of tetraploid plants were 1.6-fold larger and doubled $(P<0.001)$ in fresh weight compared with those of diploids (Fig. 3; Table 1). Flower number was only $50 \%$ in the tetraploids compared with diploids (Table 1). Novel flower morphology, including different white ray florets on the margins and tubular ray petals, was observed in a few tetraploid plants (Fig. 4), whereas most showed normal enlarged flowers. Stomatal length, width, and density showed significant

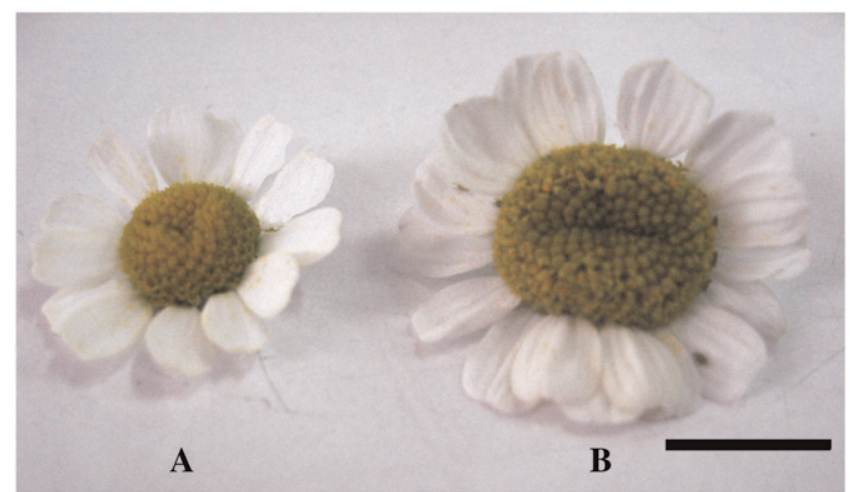

Fig. 3. Flowers of diploid (A) and tetraploid (B) Tanacetum parthenium. Bar $=1 \mathrm{~cm}$.

differences $(P<0.001$; Table 1$)$ between diploids and tetraploids. Stomatal length and width in tetraploid leaves were larger than those in diploid leaves $(81 \%$ and $90 \%$ increase, respectively; Table 1; Fig. 5). However, stomatal density was reduced to almost half in tetraploids compared with that in diploids (Table 1). Larger and wider trichomes were observed in the leaves of tetraploids compared with those of diploids (28\% and $4 \%$ increases, respectively; Table 1; Fig. 6). Trichome density in tetraploid leaves was reduced to $70 \%$ of that in diploid leaves. Pollen grains and seeds were significantly larger in the tetraploids $(32 \%$ and $61 \%$, respectively; Table 1; Figs. 7 and 8 ).

Cytological differences. Chromosome counts of root meristematic cells of diploids

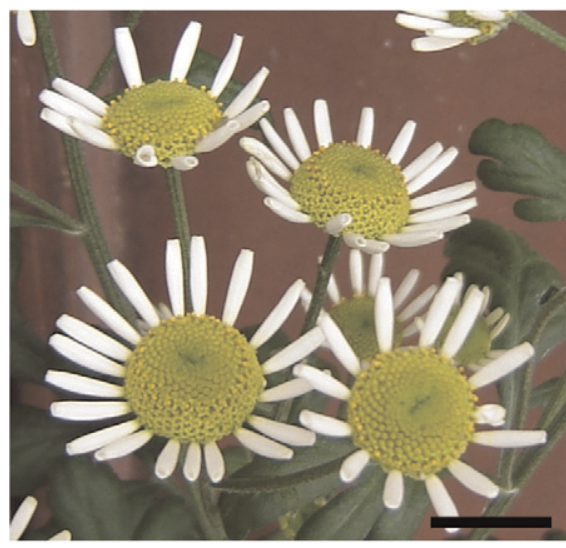

Fig. 4. Unusual flowers of tetraploid Tanacetum parthenium with long tubular petals. $B a r=1 \mathrm{~cm}$. 

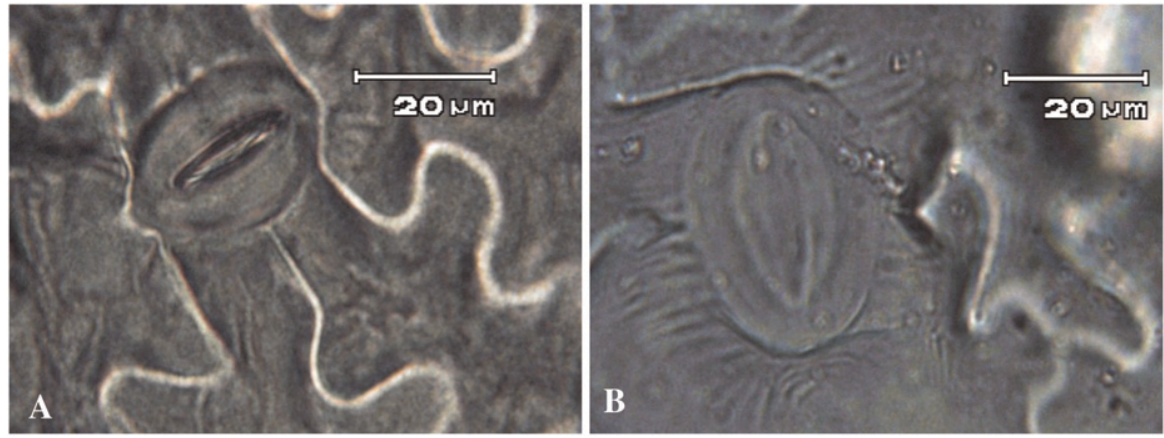

Fig. 5. Stomata of diploid (A) and tetraploid (B) Tanacetum parthenium.
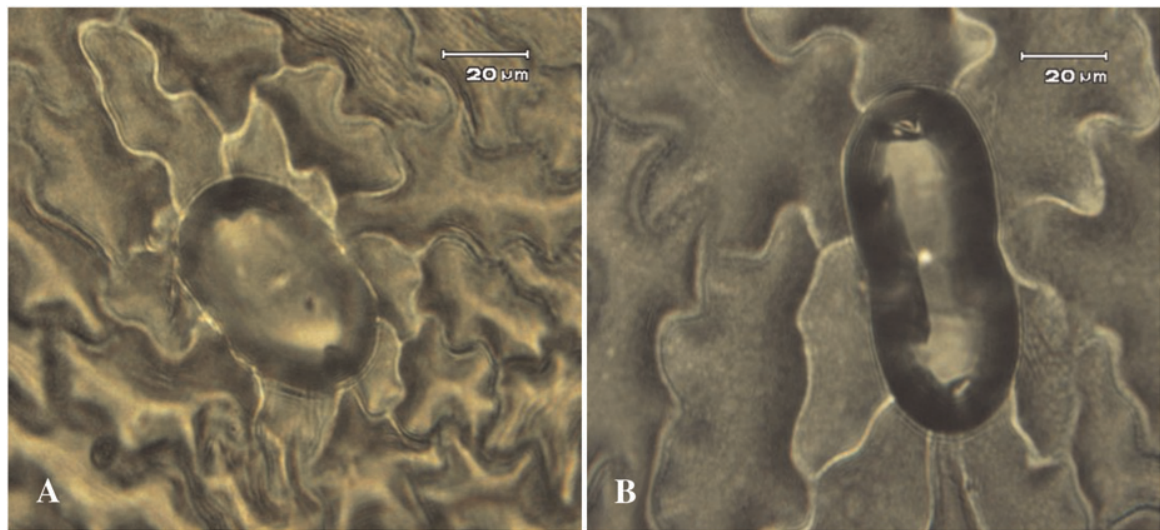

Fig. 6. Trichomes of diploid (A) and tetraploid (B) Tanacetum parthenium.
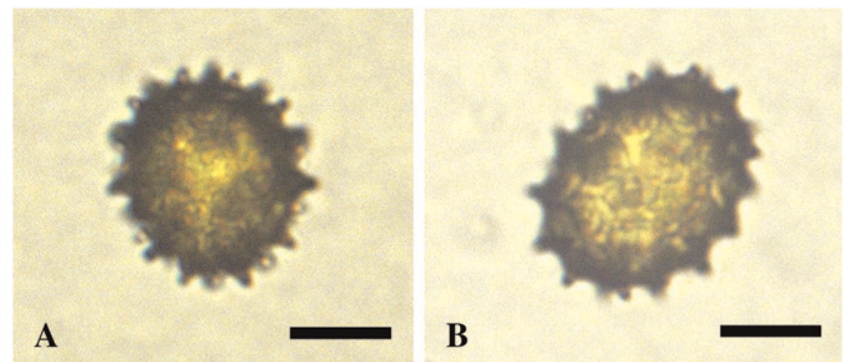

Fig. 7. Pollen grains of diploid (A) and tetraploid (B) Tanacetum parthenium. Bars $=10 \mu \mathrm{m}$.

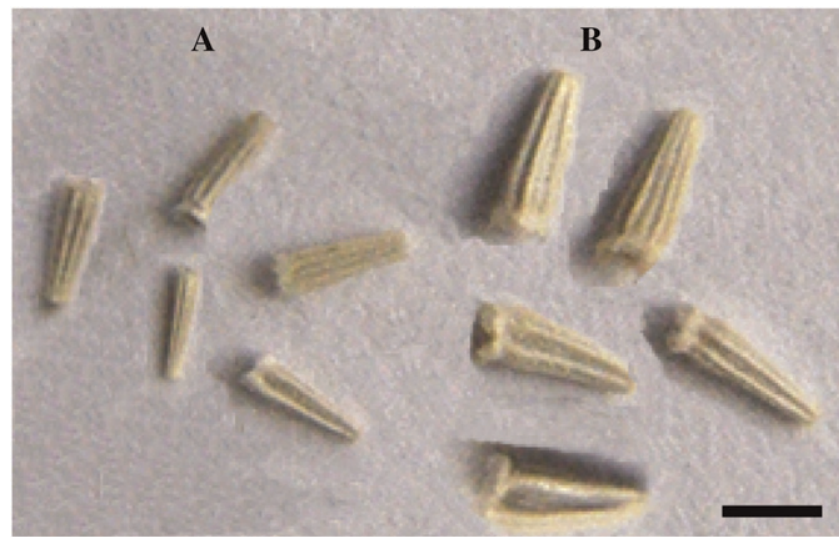

Fig. 8. Seeds of diploid (A) and tetraploid (B) Tanacetum parthenium. Bar $=1 \mathrm{~mm}$. and colchicine-treated tetraploids were examined. Chromosome number was doubled $(2 n=4 x=36)$ in the induced tetraploids compared with that of the diploids $(2 n=2 x=$ 18; Fig. 9A-B). Significantly $(P<0.001)$ larger root meristematic cells and nuclei were observed in tetraploids compared with those in diploids (44\% and 53\% increases, respectively; Table 1). From the FCM histograms, it was determined that the ratio of standard and Tanacetum parthenium peak positions in the putative tetraploid plants were nearly twice than that of the diploid plants, suggesting that chromosome duplication by treatment with colchicine was achieved with the application of colchicine. FCM analysis of tetraploids of the next generation $\left(T_{1}\right)$ gotten by selfing the $\mathrm{T}_{0}$ feverfew evidently showed no reversion of tetraploids to diploids in feverfew (Fig. 10).

Physiological and phytochemical differences. The quantum efficiency of photosystem II $\left(\mathrm{F}_{\mathrm{v}} / \mathrm{F}_{\mathrm{m}}\right)$ in tetraploid leaves was significantly $(P<0.01)$ less than that in diploid leaves. The CCI results showed a threefold increase $(P<0.001)$ in tetraploid leaves compared with that in the diploids (Table 1).

Parthenolide content was higher $(P<$ 0.01 ; Fig. 11) in the flowers than in the leaves in both ploidy types. The leaves of the diploid plants had $77 \%$ more parthenolide than those of the colchicine-treated tetraploids $\left(\mathrm{T}_{0} ; P<\right.$ 0.01 ; Fig. 11), but the reverse was true for those of tetraploids of the next generation $\left(\mathrm{T}_{1} ; P<0.01 ;\right.$ Table 2$)$. In other words, the parthenolide was doubled in the leaves of $\mathrm{T}_{1}$ tetraploids compared with that in the diploids and showed 3.5-fold increase compared with that of $\mathrm{T}_{0}$ tetraploids. In flowers, the parthenolide content was the same in $\mathrm{T}_{1}$ tetraploids in comparison with that in $\mathrm{T}_{0}$ tetraploids $(P>$ 0.05; Table 2; Fig. 12). As a whole, the parthenolide content was higher in the flowers than that in the leaves in either diploids $T_{0}$ tetraploids and $T_{1}$ tetraploids but to varying degrees.

\section{Discussion}

Polyploidy has played an important role in plant breeding as a valuable method for inducing variation and producing superior plants (Lewis, 1980; Stanys et al., 2006). Tetraploid plants are often more valuable for their improved medicinal and ornamental characteristics such as larger flowers, leaves, and increased biomass and secondary metabolites (Gao et al., 1996). This research demonstrated that viable tetraploid plants with good survival and growth performance could be produced in feverfew. The development of tetraploid feverfew may provide an avenue for the development of triploid feverfew, which may increase its productivity (Yang et al., 2006). Duration of colchicine exposure considerably affected chromosome doubling induction and survival rate. The reduction in growth rate of colchicine-treated seedlings in the first month after treatment may be the result of 


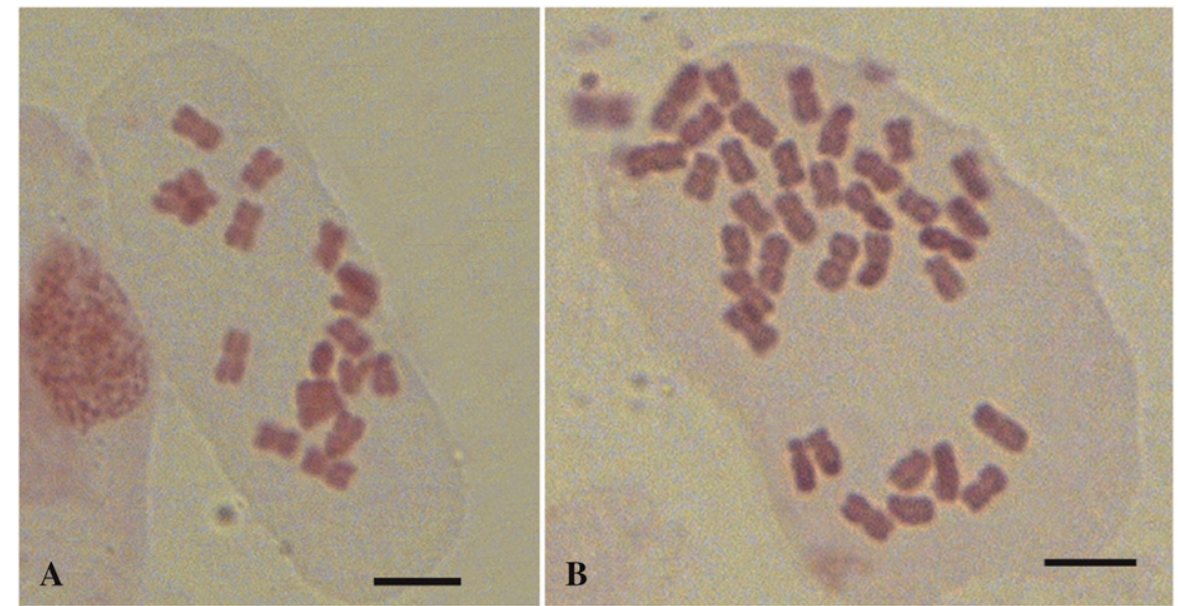

Fig. 9. Metaphase chromosome spreads of diploid $2 x=18$ (A) and tetraploid $4 x=36$ (B) Tanacetum parthenium. Bars $=5 \mu \mathrm{m}$.
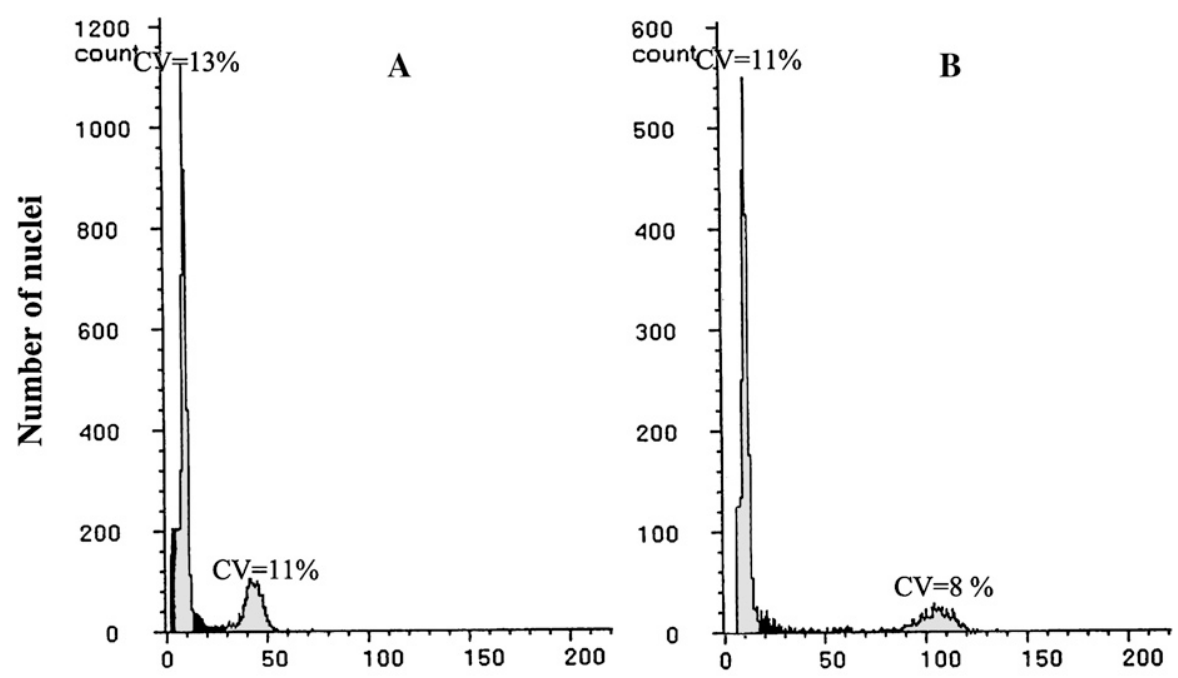

Fluorescence intensity

Fig. 10. Flow cytometric histograms of diploid (A) and tetraploid (B) Tanacetum parthenium. The left peaks refer to G1 phases of the cell cycle of standard plant (Rosa victoriana) and the right peaks to the $\mathrm{G} 1$ of sample (Tanacetum parthenium). cvs indicate the cv for each peak.

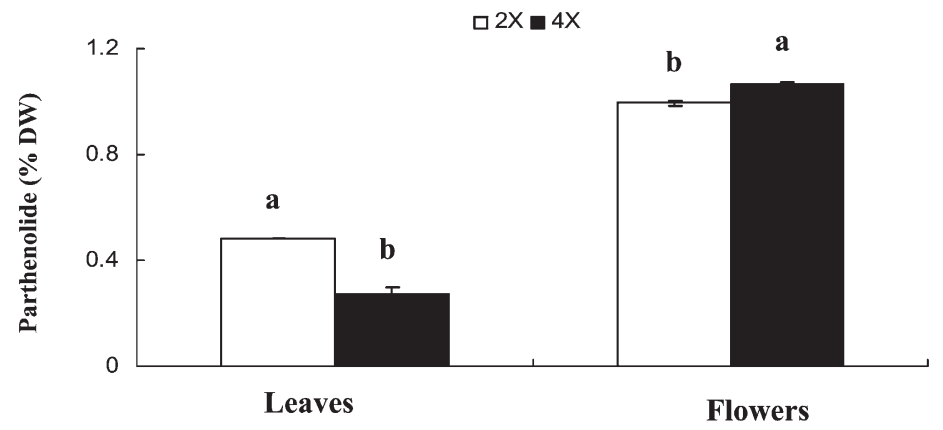

Fig. 11. Parthenolide content ( $\%$ dry weight) in Tanacetum parthenium leaves and flowers of diploids ( $2 x$, white bars) and colchicine-treated tetraploids $\left(\mathrm{T}_{0}, 4 x\right.$, black bars). Bars represent means $(\mathrm{n}=2) \pm \mathrm{SE}$. Different letters are significantly $(P<0.01)$ different according to Student's $t$ test. physiological changes caused by colchicine, which reduces the rate of cell division. Initial retardation of growth was also reported in other studies (Sikdar and Jolly, 1994; Swanson, 1957). The inverse correlation between the time of colchicine exposure and plant survival rate observed in this study was in agreement with other reports (Chakraborti et al., 1998; Sikdar and Jolly, 1994). The enlarged stomata, trichomes, leaves, flowers, pollen grains, seeds, cells, nuclear diameter, and CCI of induced tetraploid feverfew plants reported here are also observed in other plants (Takamura and Miyajima, 1996; Thao et al., 2003). In this study, increasing ploidy level increased the size of epidermal cells (stomata and trichomes) and decreased the density of them. Decrease in stomatal density in tetraploids was similar to that observed in other studies (Chakraborti et al., 1998; Khazaei et al., 2009). A positive correlation between genomic DNA amount and seed, pollen, and leaf size has been reported previously (Chung et al., 1998). A positive correlation between cell and organ size with nuclear DNA content was also reported (Leitch and Bennett, 2003). Increasing cell size resulting from tetraploidy induction may be one of the important reasons of plant organ enlargement, e.g., leaves, flowers (petals, sepals), and seeds. The positive affect of ploidy on cell size was also reported recently in tetraploid Arabidopsis in which increasing DNA content led to further cell growth (Breuer et al., 2007). The $F_{v} / F_{m}$ ratio, which was decreased by tetraploid induction in our study, can be considered a measure of the quantum efficiency of the electron transport in photosystem II. Negative correlation between photosynthetic rate and ploidy was observed in other works (Knight et al., 2005; Wullschleger et al., 1996). The CCI was positively influenced by ploidy induction. This inverse relationship between the efficiency of the electron transport in photosystem II and chlorophyll content has been demonstrated previously (Jiang and $\mathrm{Xu}$, 2000). It was determined that stomatal size measurements were the simplest parameter for identifying tetraploids at early growth stages. Stomata length and width of tetraploids were $\approx 2$-fold longer than that of diploids. Such alterations in stomatal size were similarly reported for other plants (e.g., Chakraborti et al., 1998; Sikdar and Jolly, 1994). The increase in the parthenolide content in the $T_{1}$ tetraploids indicates that the initial application of colchicine may have had a negative affect on normal growth and development in the $\mathrm{T}_{0}$ generation. Flowers maintained a higher parthenolide content production per dry weight than the leaves regardless of ploidy levels in this experiment. No reversion of $\mathrm{T}_{0}$ tertraploids to diploids and getting the healthy $\mathrm{T}_{1}$ tetraploids of feverfew showed that tetraploidy induction can be stable and increase the production of parthenloide by increasing the percent of parthenolide on a dry weight basis in both leaves and flowers. 
Table 2. Comparison of parthenolide percentage, dry weight $(\mathrm{g})$, and parthenolide amount between diploid $(2 x)$ and the tetraploids of next generation $\left(\mathrm{T}_{1}, 4 x\right)$ Tanacetum parthenium.

\begin{tabular}{lcccc}
\hline Organs & $\begin{array}{c}\text { Ploidy } \\
\text { level }\end{array}$ & $\begin{array}{c}\text { Parthenolide } \\
(\% \text { dry wt })\end{array}$ & $\begin{array}{c}\text { Dry } \\
\text { wt }(\mathrm{g})\end{array}$ & $\begin{array}{c}\text { Parthenolide } \\
\text { amount }(\mathrm{g})\end{array}$ \\
\hline Leaves & $2 x$ & $0.481 \pm 0.001 \mathrm{~b}$ & $4.883 \pm 0.19 \mathrm{~b}$ & $2.329 \pm 0.21 \mathrm{~b}$ \\
& $4 x$ & $0.950 \pm 0.050 \mathrm{a}$ & $10.066 \pm 0.92 \mathrm{a}$ & $9.485 \pm 0.56 \mathrm{a}$ \\
Significance level & & $* *$ & $* *$ & $* * *$ \\
Flowers & $2 x$ & $1.103 \pm 0.10 \mathrm{a}$ & $1.510 \pm 0.07 \mathrm{a}$ & $1.677 \pm 0.21 \mathrm{a}$ \\
& $4 x$ & $1.141 \pm 0.12 \mathrm{a}$ & $1.820 \pm 0.16 \mathrm{a}$ & $2.063 \pm 0.26 \mathrm{a}$ \\
Significance level & & NS & NS & NS
\end{tabular}

Data are means $(\mathrm{n}=3) \pm \mathrm{SE}$. Values in each vertical column, followed by different letters, are significantly different according to two-sample Student's $t$ test at: NS, ${ }^{* *}, * * *$ significance levels $(P>0.05, P<0.01$, and $P<0.001$, respectively).

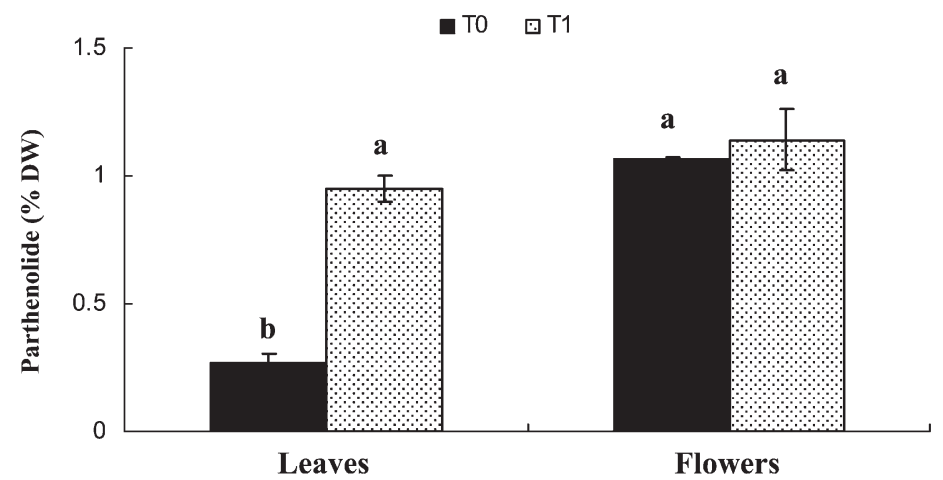

Fig. 12. Parthenolide content (\% dry weight) in Tanacetum parthenium leaves and flowers of colchicinetreated tetraploids $\left(\mathrm{T}_{0}\right.$, black bars) and the tetraploids of next generation $\left(\mathrm{T}_{1}\right.$, dotted bars). Bars represent means $(\mathrm{n}=3) \pm$ SE. Different letters are significantly $(P<0.05$ for leaves and $P<0.01$ for flowers) different according to Student's T-test.

\section{Literature Cited}

Abourashed, E.A. 2004. Validation and application of an HPTLC method for the determination of parthenolide in feverfew herbal product. $\mathrm{J}$. Planar. Chromatogr. Mod. TLC 17:375-378.

Adaniya, S. and D. Shira. 2001. In vitro induction of tetraploid Ginger (Zinger officinalis Roscoe) and its pollen fertility and germinability. Sci. Hort. 88:277-287.

Bouvier, L., F.R. Pillon, and Y. Lespinasse. 1994. Oryzalin as an efficient agent for chromosome doubling of haploid apple shoots in vitro. Plant Breed. 113:343-346.

Breuer, C., N.J. Stacey, C.E. West, Y. Zhao, J. Chory, H. Tsukaya, Y. Azumi, A. Maxwell, K. Roberts, and K. Sugimoto-Shirasu. 2007. BIN4, a novel component of the plant DNA topoisomerase VI complex, is required for endoreduplication in Arabidopsis. Plant Cell 19:3655-3668.

Brown, A., C. Edwards, T. Hartman, J. Marshall, R. Smith, M. Davey, J. Power, and K. Lowe. 1999. Sexual hybrids of Tanacetum: Biochemical, cytological and pharmacological characterization. J. Expt. Bot. 50:435-444.

Chakraborti, S.P., K. Vijayan, B.N. Roy, and S.M.H. Qadri. 1998. In vitro induction of tetraploidy in mulberry (Morus alba L.). Plant Cell Rep. 17:799-803.

Chung, J., J.H. Lee, K. Arumuganathan, G.L. Graef, and J.L. Specht. 1998. Relationship between nuclear DNA content and seed and under well-watered conditions. Genet. Resources Crop Evol. 56:105-114.

Knight, C.A., N.A. Molinari, and D.A. Petrove. 2005. The large genome constraint hypothesis: Evolution, ecology and phenotype. Ann. Bot. (Lond.) 95:177-190.

Lehrer, J.M., H.B. Mark, and D. Jessica. 2008. Lubell induction of tetraploidy in meristematically active seeds of Japanese barberry (Berberis thunbergii var. Atropurpurea) through exposure to colchicine and oryzalin. Sci. Hort. 119:67-71.

Leitch, I.J. and M.D. Bennett. 2003. Integrating genomic characters for a holistic approach to understanding plant genomes. Biology International 45:18-29.

Lewis, W.H. 1980. Ploidy: Biological relevance. Plenum Press, New York, NY. p. 180-182.

Nakano, M., T. Nomizu, K. Mizunashi, M. Suzuki, S. Mori, S. Kuwayama, M. Hayashi, H. Umehara, E. Oka, H. Kobayashi, M. Asano, S. Sugawara, H. Takagi, H. Saito, M. Nakata, T. Godo, Y. Hara, and J. Amano. 2006. Somaclonal variation in Tricyrtis hirta plants regenerated from 1-yearold embryogenic callus cultures. Sci. Hort. 110:366-371

Omidbaigi, R. 2009. Production and processing of medicinal plants, Vol. 2. Behnashr Publisher, Mashhad, Iran.

Opti-Sciences, Inc. 2002. CCM-200 chlorophyll content meter. 1 Oct. 2007. <http://www. optisci.com/ccm.htm>

Oquist, G. and R. Wass. 1988. A portable, microprocessor operated instrument for measuring chlorophyll fluorescence kinetics in stress physiology. Physiol. Plant. 73:211-217.

Palevitch, D., G. Earon, and R. Carasso. 1997. Feverfew (Tanacetum parthenium) as a prophylactic treatment for migraine: A double-blind placebo-controlled study. Phytother. Res. 11:508-511.

Sikdar, A.K. and M.S. Jolly. 1994. Induced polyploidy in mulberry (Morus spp.): Induction of tetraploids. Sericologia. 34:105-116.

Stanys, V., A. Weckman, G. Staniene, and P. Duchovskis. 2006. In vitro induction of polyploidy in Japanese quince (Chaenomeles japonica). Plant Cell Tiss. Org. Cult. 84:263268.

Swanson, C.P. 1957. Cytology and cytogenetics. Prentice Hall, Upper Saddle River, NJ.

Takamura, T. and I. Miyajima. 1996. Colchicine induced tetraploids in yellow-cyclamens and their characteristics. Sci. Hort. 65:305-312.

Thao, N.T.P., K. Ureshino, I. Miyajima, Y. Ozaki, and H. Okubo. 2003. Induction of tetraploid in ornamental Alocasia through colchicine and oryzalin treatments. Plant Cell Tissue Organ Cult. 72:19-25.

Wullschleger, S.D., M.A. Sanderson, S.B. McLaughlin, D.P. Biradar, and A.L. Rayburn. 1996. Photosynthetic rates and ploidy levels among populations of switch grass. Crop Sci. 36:306-312.

Yang, X.M., Z.Y. Cao, L.Z. An, Y.M. Wang, and X.W. Fang. 2006. In vitro tetraploid induction via colchicine treatment from diploid somatic embryos in grapevine (Vitis vinifera L.). Euphytica 152:217-224.

Yokoya, K., A.V. Roberts, J. Mottley, R. Lewis, and P.E. Brandham. 2000. Nuclear DNA amounts in roses. Ann. Bot. (Lond.) 85:557-561. 